\title{
Solute distribution in porous rhyolite as evaluated by sequential centrifugation
}

Tadashi Yokoyama ${ }^{1, *}$, Satoru Nakashima ${ }^{1}$, Takashi Murakami ${ }^{2}$, Lionel Mercury ${ }^{3}$ and Yusuke Kirino $^{1}$

* Corresponding author: tadashi@ess.sci.osaka-u.ac.jp

${ }^{1}$ Department of Earth and Space Science, Osaka University, 1-1 Machikaneyama, Toyonaka, Osaka 560-0043, Japan

${ }^{2}$ Department of Earth and Planetary Sciences, University of Tokyo, Hongo, Tokyo 113-0033, Japan

${ }^{3}$ Institut des Sciences de la Terre d'Orléans, UMR 6113 CNRS/Université D’Orléans, Tours, 1A Rue de la Férollerie, 45071 Orléans Cedex, France

Submitted to Applied Geochemistry 


\section{ABSTRACT}

Pore water in a porous rhyolite, having a porosity of $27 \%$ and pore radii ranging from $>25 \mu \mathrm{m}$ to $0.008 \mu \mathrm{m}$, was centrifugally extracted with increasing centrifugal speed stepwise to examine the potential variations of the compositions of pore water and their relationship to reaction and transport occurring in the rock. The rock was soaked for one hour to 7 days in aqueous solution prior to centrifugation. To evaluate the effect of adsorption under minimum effect of dissolution, $\mathrm{Li}^{+}$and $\mathrm{Br}^{-}$were added to the solution as tracer ions. As centrifugal speed increases, water is extracted in order of large to small pores and the thickness of residual water film becomes thinner. The concentrations of ions dissolving from the rock $\left(\mathrm{Na}^{+}, \mathrm{K}^{+}, \mathrm{Ca}^{2+}\right.$, etc. $)$ after 7 days of immersion were relatively constant in pores of $1-10 \mu \mathrm{m}$ radii and exponentially increased by $3-100$ fold with decreasing pore radius to $0.1 \mu \mathrm{m}$. These ions are dissolved from the rock and transported toward the exterior of the rock by diffusion. The calculation using a reactive-transport equation showed that the observed concentration changes reflect the change in solute distribution profile with pore size. The concentration of Si after 7 days of immersion was approximately constant or slightly decreased with increasing centrifugal speed, which appears to be controlled by the solubility. The concentration of $\mathrm{Li}^{+}$decreased with increasing centrifugal speed after one hour of immersion but the trend changed after 7 days of reaction. Initial behaviour of $\mathrm{Li}^{+}$is explained by adsorption on pore wall, and the change of trend is explained by desorption of previously adsorbed ones, slight amount of dissolution, and inflow from the outside of the rock. The change in concentration of $\mathrm{Br}^{-}$with increasing centrifugal speed was small, probably because $\mathrm{Br}^{-}$was not adsorbed on the surfaces. The sequential 
centrifuge thus provides information on the solute distribution associated with the reaction and transport occurring in rock pores. 


\section{Introduction}

Characterization of solute distribution in rock pore network is essential for quantitative analysis of water-rock interaction because the solute distribution affects the rates and mechanisms of dissolution, precipitation, adsorption, and diffusional transport. The solute distribution in rock pores often becomes inhomogeneous owing to a variety of reasons. For example, dissolution of primary minerals and formation of secondary products, which accompany diffusion of solutes, lead to the concentration gradients from the reaction front toward the exterior of rock. The surfaces of silicate minerals are often negatively charged under near neutral $\mathrm{pH}$, and cations are attracted to the surfaces and anions are expelled from the surfaces. This induces high cation concentrations and low anion concentrations near the pore wall surfaces, called the electric double layer (EDL) (e.g., Stumm and Morgan, 1996; Drever, 1997). It is important to know how and to what extent these phenomena affect the solute distribution in rock pores, but experimental visualization of such solute distribution is usually very difficult.

Centrifugation is a widely used technique to extract pore water from geological materials (e.g. Davies and Davies, 1963; Edmunds and Bath, 1976; Kinniburgh and Miles, 1983; Reynolds, 1984; Carignan et al., 1985; Saager et al., 1990; Sheppard et al., 1992; Ankley and Schubauer-Berigan, 1994; Bufflap and Allen, 1995; Azcue et al., 1997; Winger et al., 1998; Gérard et al., 2003). In extracting pore water, a variety of centrifugal speeds (or centrifugal accelerations), ranging from $<1000 \mathrm{rpm}$ to $>20000$ rpm, have been applied. Several studies have reported that the solute concentrations in pore water change depending on centrifugal speed. For example, Edmunds and Bath (1976) found that the concentrations of $\mathrm{Na}^{+}$and $\mathrm{K}^{+}$progressively decreased as a greater proportion of fluid was extracted and then upturned over the last $10-20 \%$ of extraction, 
while no distinct change of concentration was observed for $\mathrm{Mg}^{2+}$ and $\mathrm{Sr}^{2+}$. Azcue et al. (1997) showed that the concentrations of thallium ion $\left(\mathrm{Tl}^{+}\right)$in pore water of sediments extracted at $10000 \mathrm{rpm}$ and $20000 \mathrm{rpm}$ were significantly greater than those extracted at $1000 \mathrm{rpm}$ and $4000 \mathrm{rpm}$. Ankley and Schubauer-Berigan (1994) reported that the concentrations of $\mathrm{Cu}, \mathrm{Pb}$ and $\mathrm{Zn}$ in pore water extracted by low centrifugal acceleration $2500 \times \mathrm{g})(\times \mathrm{g}$ : gravitational acceleration $)$ were greater than those obtained by high centrifugal acceleration $(10000 \times \mathrm{g})$. Thus, both the increase and decrease of solute concentrations with increasing centrifugal speed have been reported. Although the reason of the centrifugal speed dependence of solute concentrations has not been discussed in detail in previous studies, it is known that water is progressively extracted in order of large to small pores as centrifugal speed increases (Edmunds and Bath, 1976). This leads to the idea that the change in solute concentration with centrifugal speed may have some information on the reaction and transport of solutes in rock pores.

The present paper uses sequential centrifugation to examine the potential variations of the compositions of pore water and their relationship to reaction and transport occurring in the rock. The chemical analysis of pore water reveals that the solute concentrations significantly change with increasing centrifugal speed and the feature of the concentration change differs by element. We explain the observed changes in solute concentrations by multiple factors including the dissolution of primary minerals and secondary salts, diffusional transport, and adsorption. For solute dissolving from the rock, we use a reaction-transport equation and show that the solute concentration, dissolution rate, diffusion rate, pore size, and centrifugal speed can be quantitatively correlated. The sequential centrifugation combined with the reaction-transport analysis can be used to estimate the dissolution rate, solubility and transport efficiency of solutes in rock pore network for studying various water-rock 
interactions including weathering (Yokoyama and Banfield, 2002) and diagenesis. In addition, the pore size dependence of dissolution and precipitation has been proposed such as from an observation of pore size dependent halite cementation in sandstones (Putnis and Mauthe, 2001) and a numerical simulation for examining the effect of pore size controlled solubility on reactive transport (Emmanuel and Berkowitz, 2007), and the sequential centrifugation may also be applicable to the researches of those phenomena.

\section{Sample description and experimental procedure}

A porous rhyolite from Kozushima, a volcanic island in Japan, was used for the experiment. The rhyolite was used because details of physical and chemical properties including size and connectivity of pores, dissolution rate, diffusivities of ions in pore water, composition, and age (erupted in 838 A.D.) have been characterized by our prior researches (Yokoyama and Banfield, 2002; Yokoyama and Nakashima, 2005; Yokoyama and Takeuchi, 2009) and because the amount of pore water and pore size distribution are appropriate to the stepwise centrifugal extraction and solution analysis (in our experimental apparatus the accuracy seems to be reduced if the solution obtained at each step is less than $\sim 0.1 \mathrm{~mL}$ ). Fig. 1a is a scanning electron microscope image of the rhyolite. The surfaces of pore walls are smooth and no alteration is detected. The porosity of the rock sample (open pores) is $26.9 \%$. Fig. $1 \mathrm{~b}$ is the cumulative pore volume ratio and pore size distribution of the sample obtained by a mercury intrusion method. The pore radii range from $8 \mathrm{~nm}$ to $25 \mu \mathrm{m}$, with a peak around 5-7 $\mu \mathrm{m}$ (measurement range: ca. $25 \mu \mathrm{m}-3 \mathrm{~nm}$ ). The rock has a specific surface area of $0.28 \mathrm{~m}^{2}$ $\mathrm{g}^{-1}$, as measured by $\mathrm{N}_{2}$ adsorption Brunauer-Emmet-Teller method (BET, FlowSorbIII 
2305, Micromeritics). The rock contains $87 \%$ glass, $8.9 \%$ plagioclase, $3.8 \%$ quartz, and $0.5 \%$ biotite with total $100.1 \%$ (vol\%) (Taniguchi et al., 1990). The whole rock chemical composition is $76.6 \% \mathrm{SiO}_{2}, 12.8 \% \mathrm{Al}_{2} \mathrm{O}_{3}, 0.10 \% \mathrm{TiO}_{2}, 0.75 \% \mathrm{FeO}, 0.60 \%$ $\mathrm{CaO}, \quad 0.07 \% \quad \mathrm{MnO}, 3.53 \% \quad \mathrm{~K}_{2} \mathrm{O}, \quad 0.05 \% \quad \mathrm{P}_{2} \mathrm{O}_{5}, 3.89 \% \quad \mathrm{Na}_{2} \mathrm{O}, 1.01 \% \quad \mathrm{H}_{2} \mathrm{O} \quad(\mathrm{wt} \%)$ (Yokoyama and Banfield, 2002). Three rock cores (core-A, core-B and core-C), having sizes of diameter $=2.40-2.48 \mathrm{~cm}$, height $=5.56-5.73 \mathrm{~cm}$, dry weight $=39.57-41.58 \mathrm{~g}$, were cut from the rock.

Fig. 2 is a schematic illustration of the apparatus used for the centrifuge. We used a high speed refrigerated centrifuge (Kubota 6500) and a stainless centrifuge tube with a plastic hollow water collection adaptor. All reagents were prepared with 'Milli-Q' water $(18.2 \mathrm{M} \Omega \mathrm{cm})$. All chemicals used were reagent-grade. At the start of the experiment, pores of two rock cores (core-A for run-A, core-B for run-B) were saturated with a 50 $\mu \mathrm{mol} \mathrm{L}{ }^{-1} \mathrm{LiBr}$ aqueous solution $(\mathrm{pH} \sim 6)$ under vacuum. To completely saturate pores, the cores were first degassed in a vacuum chamber and then the solution was inserted into the chamber to soak the cores, in the same way as Yokoyama and Takeuchi (2009). The composition of pore water is potentially affected by dissolution, adsorption and diffusional transport of solutes. The $\mathrm{LiBr}$ solution was used because $\mathrm{Li}$ and $\mathrm{Br}$ were trace constituents of the rock and their concentrations were little affected by dissolution of the rock, which serves to make the effect of adsorption clear. The effect of the 50 $\mu \mathrm{mol} \mathrm{L}{ }^{-1} \mathrm{LiBr}$ on dissolution appears to be small, which is deduced from the similarity of the results of $\mathrm{LiBr}$ solution (run-D) and pure water (run-E) as shown later. After saturating pores, the cores were soaked in 2 litres of the $\mathrm{LiBr}$ solution for 7 days at $20^{\circ} \mathrm{C}$, which was accompanied by dissolution of $\mathrm{Na}, \mathrm{K}, \mathrm{Ca}$, Si, etc. When starting centrifugal extraction, firstly the cores were taken out from the solution, their surfaces were wiped by a cleaned wet cloth, the cores were weighed to $0.0001 \mathrm{~g}$, and the total amount of pore 
water was determined by (wet mass - dry mass) for each core. The cores were then inserted into the centrifuge tubes, centrifuged at $530 \mathrm{rpm}$ for 10 minutes at $20^{\circ} \mathrm{C}$, taken out and turned upside down, and reinserted into the centrifugal tubes. This upside down was done to reduce the residual pore water extractable at each centrifugal speed. Then, the cores were centrifuged again at $530 \mathrm{rpm}$ for 10 minutes, taken out and weighed, and the volumes of the extracted pore water were determined based on the weight losses of the cores. The cores were then inserted to the centrifuge tubes again and centrifuged at higher centrifugal speed. By repeating this process, pore water was extracted at 530, 960, $1360,1920,2350,3040,4290,6070,8030$, and $9600 \mathrm{rpm}$. The centrifuge tubes were replaced by cleaned ones at every centrifugal speed to avoid mixing of the solution extracted at different centrifugal speed. The collected pore water was immediately filtered at $0.2 \mu \mathrm{m}$ to remove fine particles. The concentrations of $\mathrm{Li}^{+}, \mathrm{Na}^{+}, \mathrm{K}^{+}, \mathrm{Ca}^{2+}, \mathrm{Si}$, $\mathrm{Al}^{3+}$, total iron $\left(\mathrm{Fe}^{2+}+\mathrm{Fe}^{3+}\right), \mathrm{Br}^{-}, \mathrm{Cl}^{-}, \mathrm{NO}_{3}{ }^{-}$, and $\mathrm{NH}_{4}{ }^{+}$in the pore water were measured with an ICP-AES (SPS5100, SII) and an ion chromatography (ICA-2000, TOA-DKK). The errors in concentration measurements were typically less than $3-4 \%$, but the errors became larger for the case that the amount of extracted water was small and significant dilution was required (usually at the final extraction). $\mathrm{HCO}_{3}{ }^{-}$was a potentially major anion in the solution but its concentration was not determined because it readily changes by dissolution of atmospheric carbon dioxide. The fractions of the evaporative loss of pore water to total mass loss of the sample at each centrifugal step (the amounts of water collected plus evaporated) were estimated to be $3.5-4.9 \%$ at $1360 \mathrm{rpm}$ and $8.6-14.1 \%$ at $6790 \mathrm{rpm}$.

From the above run-A and run-B, it was found that those ions unlikely to be originated from the primary minerals of the rock, probably secondarily introduced into the rock by meteoric water etc., were detected in the extracted pore waters (shown later). 
To reduce the amount of those ions, the interior of pores were cleaned prior to the centrifugation. Firstly, the pores of a rock core (core-C) was saturated with a $0.2 \mathrm{~mol}$ $\mathrm{L}^{-1} \mathrm{HCl}$ solution, the rock was soaked in the $\mathrm{HCl}$ solution for more than 24 hour at room temperature, and the solution was extracted by centrifugation. This procedure was duplicated. Then, to remove residual $\mathrm{HCl}$, the rock was saturated with deionized water and the water was extracted by centrifugation. The extracted solution initially showed high $\mathrm{Cl}^{-}$concentration due to residual $\mathrm{HCl}$, but after repeating this procedure for eight times, the concentration of $\mathrm{Cl}^{-}$became $<10 \mu \mathrm{mol} \mathrm{L}-1$ at $6790 \mathrm{rpm}$. Then, the core was saturated with a $50 \mu \mathrm{mol} \mathrm{L}{ }^{-1} \mathrm{LiBr}$ solution (run-C), the core was soaked in the solution for seven days, and pore water was extracted by centrifugation with increasing centrifugal speed, in a similar way as run-A and run-B. In addition, to evaluate the pore water composition a short time after the injection of solution, centrifugal extraction was conducted after one hour of immersion. For this, $50 \mu \mathrm{mol} \mathrm{L}{ }^{-1} \mathrm{LiBr}$ solution (run-D) and deionized water (run-E) were used to saturate the pores of the core-C. The extracted pore water was analyzed for solute concentrations and $\mathrm{pH}$ was also measured using a micro-combination $\mathrm{pH}$ electrode in run-C (model 290Aplus equipped with 9802BN, Orion). This electrode can measure $\mathrm{pH}$ of a solution as small as $10 \mu \mathrm{L}$. To avoid possible contamination from the $\mathrm{pH}$ electrode, the extracted pore water was divided into two fractions and one was used for the analysis with ion chromatography and the other was used to determine $\mathrm{pH}$. Although $\mathrm{pH}$ was measured immediately after collecting pore water, $\mathrm{pH}$ could be affected by dissolution of atmospheric carbon dioxide because we did not use buffer solution. The experimental conditions are summarized in Table 1.

A zeta potential of the powdered rhyolite in distilled water was measured to be $-38.5(+2.5,-1.8) \mathrm{mV}$ at $25^{\circ} \mathrm{C}$ by a zeta potential analyzer (ZetaPALS, Brookhaven). It is thus presumed that the pore walls of the rhyolite are negatively charged in the present 
experimental conditions, although the composition of pore water is different from distilled water to some extent and the actual zeta potential of pore walls might be slightly different from the measured value.

\section{Centrifugal speed and pore water retention}

The water retained in rock pore can be distinguished into two types: (i) capillary water, making pore filled and (ii) water films, making pore wall wet. Previous research has proposed that pore water is extracted in order of large to small pores as centrifugal force increases (Edmunds and Bath, 1976). Consider a column of water-saturated pore whose radius is $r_{\text {pore }}(\mathrm{m})$ and column axis is parallel to centrifugal force (Fig. 2). The centrifugal force applied to a small interval within the water column located at a distance $R$ from the centrifugal axis, $d F_{\text {cent }}(R)(\mathrm{N})$, is expressed as

$d F_{\text {cent }}(R)=R \omega^{2} \rho \pi r_{\text {pore }}^{2} d R$,

where $\rho$ is the density of water $\left(998 \mathrm{~kg} \mathrm{~m}^{-3}\right)$ and $\omega$ the centrifugal speed $\left(\mathrm{rad} \mathrm{s}^{-1}\right)$. The total centrifugal force applied to the water column, $F_{c e n t}$, can be obtained by integrating $d F_{\text {cent }}(R)$ from the bottom of water column to the top as

$$
F_{\text {cent }}=\int_{R_{2}}^{R_{1}} d F_{\text {cent }}(R)=\rho \pi r_{\text {pore }}^{2} \omega^{2} \frac{\left(R_{1}^{2}-R_{2}^{2}\right)}{2}
$$

where $R_{1}$ and $R_{2}$ are the distances from the centrifugal axis to the bottom and top of water column, respectively. If eq. (2) is divided by the sectional area of the water column and $\rho g$ ( $g$ : gravitational constant), the applied tension (in units of height of water) (Richard and Weaver, 1944; Edmunds and Bath, 1976) is obtained. When a 
centrifugal force is applied to the water column, a capillary force arises in the opposite direction to the centrifugal force (Fig. 2). The capillary force $F_{c a p}(\mathrm{~N})$ is expressed as: $F_{\text {cap }}=2 \pi r_{\text {pore }} \gamma \cos \theta$,

where $\gamma\left(=72.75 \times 10^{-3} \mathrm{~N} \mathrm{~m}^{-1}\right)$ is the surface tension of water and $\theta$ the contact angle. Since $F_{c e n t}$ needs to be larger than $F_{c a p}$ for water to be extracted, the smallest $r_{\text {pore }}$ from which water is extracted under a centrifugal speed $\omega$ is $r_{\text {pore }}=\frac{4 \gamma \cos \theta}{\rho \omega^{2}\left(R_{1}^{2}-R_{2}^{2}\right)}$.

The values of $r_{\text {pore }}$, calculated using $R_{1}=7.4 \times 10^{-2} \mathrm{~m}$ and $R_{2}=4.6 \times 10^{-2} \mathrm{~m}$, are shown in Table 2. $\theta$ was assumed to be $0^{\circ}$, in common with the work of Edmunds and Bath (1976). As centrifugal speed increases, water is extracted in order of large to small pores. The cumulative amount of pore water extracted at each $r_{\text {pore }}$ in the centrifugation is compared with the result of mercury intrusion measurement in Fig. 1b. The above calculation of $r_{\text {pore }}$ assumed that the column of pore water having a radius of $r_{\text {pore }}$ is connected from one edge of the rock to the other edge. Although actual length of pore water may have variation, the good accordance in Fig. 1b suggests that the above assumptions are reasonable. Fig. 3 shows schematic images of pore size distributions of water-filled pores and unfilled pores under centrifugal speeds of $960 \mathrm{rpm}$ (a) and 6070 $\operatorname{rpm}(\mathrm{b})$.

For pores only wetted (non-filled pores whose surfaces are wet with water film), the thickness of the water film is related both to the solvent-substrate interactions and to the suction applied to the water film. This suction can be exerted by increase of air dryness or by other physico-chemical mean including the centrifugation. The centrifugal 
force $F_{c e n t}$ applied to the pore water having a radius of $r_{\text {pore }}$ (cf. Eqs. (2) and (4)) can be converted into an air dryness scale using the Kelvin relation:

$$
\frac{R T}{V_{\mathrm{w}}} \ln \frac{R H}{100}=\frac{R T}{V_{\mathrm{w}}} \ln \frac{p}{p^{\circ}}=-\frac{2 \gamma}{r_{\text {pore }}}=-\frac{F_{c e n t}}{\pi r_{\text {pore }}^{2}}=\Psi_{\text {cap }},
$$

where $R$ is the gas constant $\left(\mathrm{J} \mathrm{K}^{-1} \mathrm{~mol}^{-1}\right), T$ the absolute temperature $(\mathrm{K}), V_{\mathrm{w}}$ the molar volume of water $\left(\mathrm{m}^{3} \mathrm{~mol}^{-1}\right), R H$ the relative humidity (unitless), $p / p^{\circ}$ the ratio of the actual to the saturated partial pressure of vapour in air (unitless), and $\Psi_{\text {cap }}$ the capillary potential $(\mathrm{kPa})$. This equivalent air humidity enables us to use so-called disjoining pressure $\Pi(h)$ (Derjaguin et al., 1987), a thermodynamic parameter that correlates the thickness of water film $h(\mathrm{~m})$ and air humidity (e.g. Iwamatsu and Horii, 1996; Tuller et al., 1999; Churaev, 2003):

$$
\Pi(h)=\Pi_{\mathrm{m}}(h)+\Pi_{\mathrm{s}}(h)+\Pi_{\mathrm{e}}(h)=-\frac{R T}{V_{\mathrm{w}}} \ln \frac{p}{p^{\circ}},
$$

$\Pi(h), \Pi_{\mathrm{m}}(h), \Pi_{\mathrm{s}}(h), \Pi_{\mathrm{e}}(h)$ : disjoining pressure and its molecular, structural, and electrostatic components of a thin water film $\left(\mathrm{N} \mathrm{m}^{-2}\right)$. Details on the latter three components are described in Appendix. The film thickness evaluated using Eqs (5) and (6) decreased with increasing centrifugal speed (Table 2). The result of calculation revealed that the amount of solutions estimated from the film thickness accounts for maximum $1.3 \%$ of the total amount of pore water extracted at each centrifugal speed. Thus, the effect of water film thinning on pore water composition can be virtually disregarded.

\section{Results}


The experimental results are summarized in Table 3 and the solute concentrations after 7 days of immersion are plotted against the extraction ratio in Fig. 4. The solute concentrations at the extraction ratio of $0 \%$ correspond to those of the outside of the rock after 7 days of immersion, and thus, were low for all the solutes except for the additive $\mathrm{Li}^{+}$and $\mathrm{Br}^{-}$. As a general trend, the concentrations were relatively constant or changed moderately at lower centrifugal speeds (extraction ratios of $\sim 0-70 \%, \mathrm{r}_{\text {pore }}>\sim 1$ $\mu \mathrm{m},<3000 \mathrm{rpm})$ and exponentially rose with increasing centrifugal speed at higher centrifugal speeds (extraction ratios of $\sim 70-90 \%, \mathrm{r}_{\text {pore }} \sim 1-0.1 \mu \mathrm{m}, 3000-9600 \mathrm{rpm}$ ). Both sharp rise and fall were observed at the final extraction. The concentrations of $\mathrm{Na}^{+}$, $\mathrm{K}^{+}, \mathrm{Ca}^{2+}, \mathrm{Al}^{3+}$, and $\mathrm{Fe}_{\text {total }}$, cations that may dissolve from the rock, approximately followed the general trend. The concentration profile of Si differed from those of the other ions; rapid increase in concentration at high extraction ratios was not observed. In run- $\mathrm{C}$, the concentration of $\mathrm{Si}$ somewhat decreased at extraction ratio of $\sim 70-90 \%$ and then rose up again at the final extraction. Although the decrease of Si concentration at high extraction ratios observed in run- $\mathrm{C}$ was not obvious in run- $\mathrm{A}$ and run- $\mathrm{B}$, the same trend as in run- $\mathrm{C}$ was often observed in our several trial experiments. As to the additive $\mathrm{Li}^{+}$and $\mathrm{Br}^{-}$, the concentration profiles of $\mathrm{Li}^{+}$in runs $\mathrm{A}-\mathrm{C}$ were approximately similar to the general trend. In contrast, the change in concentrations of $\mathrm{Br}^{-}$with increasing extraction ratio was small. $\mathrm{pH}$ were approximately constant at $\sim 5.5$ at any extraction ratio in run-C.

The concentrations of $\mathrm{NH}_{4}^{+}, \mathrm{Cl}^{-}$and $\mathrm{NO}_{3}^{-}$, those ions likely secondarily introduced into the rock, whether they are biogenic or not is uncertain, showed similar trends to the general one. The concentrations of $\mathrm{NH}_{4}{ }^{+}$and $\mathrm{NO}_{3}{ }^{-}$were markedly high in run- $\mathrm{A}$ and run-B, whereas they were low in run-C. This clearly shows that these ions were removed by cleaning, although the concentrations of $\mathrm{NH}_{4}{ }^{+}$somewhat increased at 
high extraction ratios probably due to residual fractions. The effect of cleaning was less apparent for $\mathrm{Cl}^{-}$. This may indicate that $\mathrm{Cl}^{-}$was not removed easily by the cleaning or that complete removal of the residual $\mathrm{HCl}$ used in the cleaning was difficult even by repeated cleaning using deionized water.

The results of centrifugal extraction after one hour of immersion are compared with those of 7 days of immersion in Fig. 5. After one hour of immersion in $\mathrm{LiBr}$ solution (run-D), the concentration of $\mathrm{Li}^{+}$decreased with increasing extraction ratio, and the rapid rise in concentration at high extraction ratios as seen in 7 days of immersion (run-C) was not observed. In contrast, the change in concentration of $\mathrm{Br}^{-}$in run-D was relatively small and the trend was similar to that in run-C. In the experiment using pure water (run-E), the concentrations of $\mathrm{Li}^{+}$were low at low to medium extraction ratios and slightly increased at high extraction ratio. This implies that a slight amount of $\mathrm{Li}^{+}$ dissolved from the rock. The concentration of $\mathrm{Br}^{-}$in run- $\mathrm{E}$ was under the detection limit $\left(\sim 0.1 \mu \mathrm{mol} \mathrm{L} \mathrm{L}^{-1}\right)$ at any extraction ratio, ensuring no dissolution of $\mathrm{Br}^{-}$. The concentrations of $\mathrm{Si}$ in run-D and run-E seemed to be on the way to rise to the values of run-C. The concentrations of $\mathrm{Na}^{+}, \mathrm{K}^{+}$and $\mathrm{Ca}^{2+}$ at the extraction ratios of $<80 \%$ were approximately similar among run-C, run-D and run-E, but exponential increase in concentration at higher extraction ratio as in run-C was not observed in run-D and run-E.

\section{Discussion}

When water permeates into rock pores, dissolution of elements occurs at the solid-solution interfaces. These elements diffuse through pores and the concentration gradients from the solid-solution interfaces toward the outside of the rock are formed. 
The source of dissolved ions may be not only the primary minerals but also the secondary products including salts and clays. Immersion of the rock prior to the centrifugation is reproducing such water-rock interaction in natural aquatic environment. In interpreting the result of centrifugation, we first consider the effects of the dissolution and diffusion. Fig. 6 shows a model illustration of the extraction process of rock pore solution with stepwise increase of centrifugal speed, taking account of the effects of dissolution and diffusion. As centrifugal speed increases, the composition of the extracted solution shifts to that of smaller pores. It is also possible to regard that the composition approaches that at dissolution/diffusion front with increasing centrifugal speed, because pore water comes closer to the solid-water interface as pore size decreases. To quantitatively correlate the solute concentration, dissolution rate, diffusion rate and pore size, we consider a simple model treating the dissolution and transport in the rock. In Fig. 6, it is assumed that pore is a tube with a radius of $r_{\text {pore }}$ and the elements dissolved from the pore wall are transported to the exterior of the rock by diffusion. The mass balance in the pore is described by

$\frac{\partial c}{\partial t}=D_{0} \frac{\partial^{2} c}{\partial x^{2}}+\frac{R_{\text {diss }} \cdot 2 \pi r_{\text {pore }} \delta x}{\pi r_{\text {pore }}^{2} \delta x}=D_{0} \frac{\partial^{2} c}{\partial x^{2}}+\frac{2}{r_{\text {pore }}} R_{\text {diss }}$,

where $c$ is the concentration of solute in pore water $\left.(\mathrm{mol} \mathrm{cm})^{-3}\right), t$ the time from the start of the immersion of the rock (sec), $x$ the position in the rock $(x=0$ and $x=L$ are taken as the edge of the rock) $(\mathrm{cm}), D_{0}$ the self-diffusion coefficient of the solute $\left(\mathrm{cm}^{2} \mathrm{sec}^{-1}\right), R_{\text {diss }}$ the dissolution rate of the solute from the rock $\left(\mathrm{mol} \mathrm{cm} \mathrm{cm}^{-1}\right)$. Tortuosity of pore is not considered in eq. (7). The solution of eq. (7) under an initial condition of $c(x, 0)=0$ and boundary conditions of $c(0, t)=c(L, t)=0$ is 


$$
c(x, t)=\frac{R_{\text {diss }}}{r_{\text {pore }} D_{0}}(L-x) x-\sum_{n=1}^{\infty}\left\{\frac{R_{\text {diss }}}{r_{\text {pore }} D_{0}} \frac{8 L^{2}}{\pi^{3}(2 n-1)^{3}} \sin \frac{(2 n-1) \pi x}{L} \exp \left(-\frac{D_{0}(2 n-1)^{2} \pi^{2} t}{L^{2}}\right)\right\}
$$

Here, we see about the dissolution and transport of sodium ion. The self-diffusion coefficient of $\mathrm{Na}$ at infinite dilution at $18^{\circ} \mathrm{C}$ is reported to be $1.13 \times 10^{-5} \mathrm{~cm}^{2} \mathrm{sec}^{-1}$ ( $\mathrm{Li}$ and Gregory, 1974), and for $20^{\circ} \mathrm{C} D_{0}$ of $1.20 \times 10^{-5} \mathrm{~cm}^{2} \mathrm{sec}^{-1}$ is obtained from the following Stokes-Einstein relation: $\left(D_{0} \eta / T\right)_{T_{1}}=\left(D_{0} \eta / T\right)_{T_{2}}$, where $\eta$ is the viscosity of water $\left(0.001056 \mathrm{~Pa} \cdot \mathrm{sec}\right.$ at $18^{\circ} \mathrm{C}$ and $0.001005 \mathrm{~Pa} \cdot \mathrm{sec}$ at $\left.20^{\circ} \mathrm{C}\right)$ and $\mathrm{T}$ the absolute temperature. When this $D_{0}$ and $L=2.4 \mathrm{~cm}$ (diameter of the rock core) are used, the second term in the right-hand side of eq. (8) becomes negligibly small at $t>3$ day and the concentration profile can be simply described by the first term. As to $R_{\text {diss }}$, a previous study on dissolution experiment of the rhyolite powder (Yokoyama and Banfield, 2002) showed that the dissolution rate of $\mathrm{Si}$ at $20^{\circ} \mathrm{C}$ is $5 \times 10^{-17} \mathrm{~mol} \mathrm{~cm}^{-2} \mathrm{sec}^{-1}$ and for the initial ten days of reaction the dissolution rate of $\mathrm{Na}$ at $50^{\circ} \mathrm{C}$ is faster than that of Si by a factor of $1-1.3$. Then, $R_{\text {diss }}$ of $\mathrm{Na}$ is estimated to be $\sim 5 \times 10^{-17} \mathrm{~mol} \mathrm{~cm}^{-2}$ $\mathrm{sec}^{-1}$. Fig. 7 shows concentration profiles of $\mathrm{Na}$ for $r_{\text {pore }}=0.5,1.0$ and $10 \mu \mathrm{m}$ calculated using a dissolution rate of $5 \times 10^{-17} \mathrm{~mol} \mathrm{~cm}^{-2} \mathrm{sec}^{-1}$. The average concentration for each pore radius $c_{\text {ave }}\left(\mathrm{mol} \mathrm{cm}^{-3}\right)$, described as dotted lines, can be calculated as

$$
C_{\text {ave }}=\frac{1}{L} \int_{0}^{L} \frac{R_{\text {diss }}}{r_{\text {pore }} D_{0}}(L-x) x d x=\frac{R_{\text {diss }} L^{2}}{6 r_{\text {pore }} D_{0}} .
$$

This $C_{\text {ave }}$ is considered to correspond to the Na concentration of the solution extracted at the given centrifugal step. By use of Eq. (9), we can deduce the change in solute concentration with increasing centrifugal force. Fig. 8 shows the calculated changes in $\mathrm{Na}$ concentration with changing pore radius (extraction ratio), together with the results 
of centrifugal extraction. The profiles were calculated using a dissolution rate of $3 \times 10^{-17} \mathrm{~mol} \mathrm{~cm}^{-2} \mathrm{sec}^{-1}$ and fivefold and one-fifth of the value. The experimental result is fitted well by the calculated profile using the dissolution rate of $3 \times 10^{-17} \mathrm{~mol} \mathrm{~cm} \mathrm{~cm}^{-2}$ $\mathrm{sec}^{-1}$, which approximately agrees with the result of dissolution experiment (Yokoyama and Banfield, 2002). It should be noted that if pore shape is not an ideal tube and wide portion is present within a narrow pore, depending on the size, position and number of the wide portion, overall concentration may change from the case assuming a constant radius through the pore. The discrepancy between calculated profile and experimental result is observed especially at low centrifugal speed and this might be related to the deviation from ideal tube. However, it may be reasonable to consider from Fig. 8 that for solutes dissolving from the rock the increase of concentrations with centrifugal speed basically reflects the pore-size dependence of the solute distribution profile stemming from dissolution and diffusion.

In Fig. 4, rapid increases of the concentrations of $\mathrm{Na}^{+}, \mathrm{K}^{+}, \mathrm{Ca}^{2+}, \mathrm{Al}^{3+}, \mathrm{Fe}^{2+}+\mathrm{Fe}^{3+}$, $\mathrm{NH}_{4}^{+}, \mathrm{Cl}^{-}$, and $\mathrm{NO}_{3}^{-}$at extraction ratios of $\sim 70-90 \%$ were observed. These concentration changes may be mainly related to the dissolution of primary minerals and secondary salts. The concentrations of $\mathrm{NH}_{4}{ }^{+}$and $\mathrm{NO}_{3}{ }^{-}$had similar trends in run-A and run-B and significantly decreased by the cleaning (run-C). Since the concentrations of ions that are only included in salts are expected to decrease by the cleaning, it seems that $\mathrm{NH}_{4}{ }^{+}$and $\mathrm{NO}_{3}{ }^{-}$formed a salt and behaved as a pair. The effect of cleaning was less apparent for $\mathrm{Cl}^{-}$. Some of $\mathrm{Cl}^{-}$might be present as salt (others as residual $\mathrm{HCl}$ ), but it is unclear with which cation $\mathrm{Cl}^{-}$formed salt. The change in concentrations before and after the cleaning was relatively small for $\mathrm{Na}^{+}, \mathrm{K}^{+}$and $\mathrm{Ca}^{2+}$. For these cations, the dissolution of primary minerals appears to largely contribute to the concentration changes, although the dissolution of salts may also have some contribution. The 
concentrations of $\mathrm{K}^{+}, \mathrm{Ca}^{2+}$ and $\mathrm{Cl}^{-}$decreased in initial several centrifugal steps and then gradually increased. A possible explanation for this might be the presence of a narrow pore that has a wide entrance. If such pore is present, the water at the wide entrance has low capillary force and can extrude the water in narrow portion (narrow portion does not become empty because it has high capillary force), so some amount of water in narrow portion comes out at low centrifugal speed. This can increase solute concentration at low centrifugal speed because the narrow portion has high concentration. At the final extraction, both sharp rise and fall of concentration were observed even for a single ion species. Since the amount of water extracted at the final extraction was very small $(1.5-3.5 \%$ of total pore water, Table 3$)$ compared with the other extraction step, its composition may be significantly affected by mixing with small amount of solution remaining in larger pores. This makes it difficult to interpret the data of the final extraction.

The concentration of $\mathrm{Li}^{+}$after one hour of immersion (run-D) decreased with increasing centrifugal speed (Fig. 5). It is clear that this trend cannot be explained by the dissolution. Fig. 9 shows a model illustration of the time variation of the distribution of $\mathrm{Li}^{+}$in pore water. When the solution containing $\mathrm{LiBr}$ was injected into pores, $\mathrm{Li}^{+}$can be adsorbed on negatively charged pore surfaces in relatively short time after the injection. If pore water is centrifugally extracted after the adsorption, some of the adsorbed $\mathrm{Li}^{+}$ may be retained at the pore surfaces and the concentration of $\mathrm{Li}^{+}$in the extracted pore water decreases. Since smaller pores have greater surface to volume ratio, $\mathrm{Li}^{+}$ concentration would be more decreased as pore size decreases. Thus, the decrease of $\mathrm{Li}^{+}$ concentration at higher centrifugal speed after one hour of immersion (Fig. 5; run-D) appears to be explained by the effect of adsorption. As time passes after the initial adsorption, diffusional inflow of $\mathrm{Li}^{+}$from the outside of the rock toward smaller pores 
may occur. At the same time, some of $\mathrm{Li}^{+}$adsorbed in the early period of the immersion may desorb. This is because the concentrations of other cations $\left(\mathrm{Na}^{+}, \mathrm{K}^{+}, \mathrm{Ca}^{2+}\right.$, etc) increase with time due to dissolution and this can affect the adsorption condition of $\mathrm{Li}^{+}$. It may be also possible that small amount of $\mathrm{Li}^{+}$dissolved from the rock during 7 days of immersion. The increase of the concentration of $\mathrm{Li}^{+}$at higher extraction ratios after 7 days of immersion (Figs 4 and 5; runs $\mathrm{A}-\mathrm{C}$ ) can thus be explained. With regard to the adsorption, EDL arises near the pore surfaces and cations are attracted to the surfaces and anions are expelled from the surfaces, by which the concentration gradient from bulk pore water toward the pore surfaces is formed. The characteristic thickness of the ion distribution from the surface to bulk solution, Debye length, was estimated to be no more than $\sim 22 \mathrm{~nm}$, based on the Gouy-Chapman theory (e.g., Stumm and Morgan, 1996) with an ionic strength of $2 \times 10^{-4}$, approximately corresponding to those at extraction ratios of $30-60 \%$ (Table 3 ). Since the calculated thickness is rather small compared to pore radii $(>\sim 100 \mathrm{~nm})$, it seems that the cations distributed near the surface and those attaching at the surfaces can be equally regarded as adsorbed ones in interpreting the results of centrifugation. The concentration of $\mathrm{Br}^{-}$was little affected by centrifugal speed both after one hour and 7 days of immersion (Fig. 5). This may be because the anion is not adsorbed on the surfaces.

The concentrations of Si were relatively constant at extraction ratios of $>20 \%$ in run-A and run-B (Fig. 4) and rapid increase of concentration at extraction ratios of $\sim 70-90 \%$, which was seen in many ions, was not observed. Thermodynamic calculations for the results of run-A and run-B ( $\mathrm{pH}$ was assumed as 5.5) using PHREEQC software (Parkhurst and Appelo, 1999) with minteq database revealed that the solutions at extraction ratios of $>20 \%$ are supersaturated with respect to Si bearing secondary products such as kaolinite and halloysite. For example, the saturation indices 
of halloysite at extraction ratios of $18-78 \%$ and $85-90 \%$ in run-A are $1.3-1.6$ and 2.6-3.1, respectively, where the halloysite is the most abundant weathering products observed in weathered rhyolites in Kozushima (Yokoyama and Banfield, 2002). Thus, the concentration of Si appears to be controlled by formation of secondary products. In run-C, up-down-up behaviour of $\mathrm{Si}$ was observed. Under the thermodynamic equilibrium at $\mathrm{pH} 5-7$, a dominant aqueous $\mathrm{Si}$ species is calculated to be electrically neutral $\mathrm{Si}(\mathrm{OH})_{4}$, based on the equilibrium constants in Sjöberg (1996). It may be also possible that some $\mathrm{Si}$ are in the form of anion, because silicates in the rhyolite may firstly dissolve as polymeric anionic species and depolymerisation is completed only $50 \%$ after $\sim 3$ hours at $\mathrm{pH} 5.5$ (Dietzel and Usdowski, 1995; Dietzel, 2000). Since Si is at least not present as cationic species, the up-down-up behaviour of Si is unlikely to be attributed to the effect of adsorption. As another factor, it has been indicated that the solubility of minerals in porous media decreases with decreasing pore sizes (Iler, 1979; Dandurand et al., 1982; Rimstidt and Cole, 1983; Mizele et al., 1985; Mercury et al., 2003). Mizele et al. (1985) extracted pore water in pastes of amorphous silica under various gas pressures and showed that the solubility decreases by $\sim 30 \%$ as pore size decreases from $30 \mu \mathrm{m}$ to $0.01 \mu \mathrm{m}$. However, based on their data, the decrease of solubility for the smallest pore in our study $(0.09 \mu \mathrm{m})$ is estimated to be $\sim 6 \%$. The effect may be therefore limited, although such decrease of solubility might be partly related to the decrease of $\mathrm{Si}$ concentration at pores of $\sim 1 \mu \mathrm{m}$ down to $\sim 0.2 \mu \mathrm{m}$ radii. The re-increasing trend at the smallest pores cannot be attributed to the effect of solubility because the concentration of $\mathrm{Si}$ is expected to continuously decrease with decreasing pore size. The re-increasing trend may be explained by the proximity of the ongoing dissolution/diffusion at the solid-water interface. 
When pore water is extracted for conducting thermodynamic and kinetic analyses of water-rock interaction, bulk pore water is usually extracted. However, the result of sequential centrifuge revealed that the composition of pore water significantly varies depending on pore size. We showed that for solute dissolving from the rock the increase of concentrations with centrifugal speed basically reflects the pore-size dependence of the solute distribution stemming from dissolution and diffusion. It is inferred that how solute distribution in rock pore is formed significantly changes depending on the mineral composition and pore structure. The sequential centrifugation is an effective method to evaluate such solute distribution. Future studies on sequential centrifugation for various rocks are required to reveal how the pore-size dependence of solute distribution affects the rate and mechanism of water-rock reactions, but such knowledge might contribute to an advanced understanding of water-rock reactions.

\section{Conclusions}

Pore water in a porous rhyolite was centrifugally extracted with increasing centrifugal speed and changes in solute concentrations were evaluated. As centrifugal speed increases, water is extracted in order of large to small pores and the thickness of water film becomes thinner. The concentrations of ions dissolving from the primary minerals and secondary salts $\left(\mathrm{Na}^{+}, \mathrm{K}^{+}, \mathrm{Ca}^{2+}\right.$, etc. $)$ after 7 days of immersion were generally relatively constant in pores of $1-10 \mu \mathrm{m}$ radius and rapidly increased by $3-100$ fold with decreasing pore radius to $0.1 \mu \mathrm{m}$. A calculation using reactive-transport equation suggests that these concentration changes reflect the pore-size dependence of the solute distribution profile associated with dissolution and diffusional transport. The concentration of $\mathrm{Li}^{+}$in smaller pores initially decreased but later increased. This seems 
to be explained by the initial adsorption of $\mathrm{Li}^{+}$on the negatively charged pore surfaces and subsequent desorption, dissolution and diffusional inflow of $\mathrm{Li}^{+}$from the outside of the rock. The concentration of $\mathrm{Br}^{-}$was little affected by centrifugal speed, probably because the anion is not adsorbed on the surfaces. The sequential centrifugation is an

effective method to examine the solute distribution in pores of various sizes, and increase of the data of various rocks has a potential to contribute to an advanced understanding of water-rock reactions.

\section{Acknowledgements}

The manuscript was greatly improved by the comments of two anonymous reviewers. Thanks are due to M. Takahashi for help in mercury intrusion method measurement. The zeta potential of the rhyolite was measured at Nikkiso Co Ltd. This research was supported financially by Japan Ministry of Education, Science, Sports and Culture, Grant-in-Aid for Young Scientists (B) 18740338, 2007 through TY. 


\section{References}

Ankley, G.T., Schubauer-Berigan, M.K., 1994. Comparison of techniques for the isolation of sediment pore water for toxicity testing. Arch. Environ. Contam. Toxicol. 27, 507-512.

Azcue, J.M., Cheam, V., Lechner, J., 1997. Effects of centrifugation speed on measurements of thallium in sediment pore water. Int. J. Environ. Analytic. Chem. $66,61-70$

Bufflap, S.E., Allen, H.E., 1995. Sediment pore water collection methods for trace metal analysis: a review. Wat. Res. 29, 165-177.

Carignan, R., Rapin, F., Tessier, A., 1985. Sediment porewater sampling for metal analysis: a comparison of techniques. Geochm. Cosmochim. Acta 49, 2493-2497.

Churaev, N.V., Derjaguin, B.V., 1985. Inclusion of structural forces in the theory of stability of colloids and films. J. Colloid Interf. Sci. 103, 2, 542-553.

Churaev, N.V., 2003. Surface forces in wetting films. Colloid. J. 65, 3, 263-274.

Dandurand, J.-L., Mizele, J., Schott, J., Bourgeat, F., Valles, V., Tardy, Y., 1982.

Premiers résultats sur la solubilité de la silice amorphe dans les pores de petite taille. Variation du coefficient d'activité de la silice en fonction de l'activité de l'eau. Sci. Géol. Bull. 35, 71-79.

Davies, B.E., Davies, R.I., 1963. A simple centrifugation method for obtaining small samples of soil solution. Nature 198, 216-217.

Derjaguin, B.V., Churaev, N.V., Muller, V.M., 1987. Surface forces. Consult. Bureau, Plenum Pub. Co., New York. 440 pp.

Dietzel, M., Usdowski, E., 1995. Depolymerisation of soluble silicate in dilute aqueous solutions. Colloid. Polym. Sci. 273, 590-597. 
Dietzel, M., 2000. Dissolution of silicates and the stability of polysilicic acid. Geochim. Cosmochim. Acta 64, 3275-3281.

Drever, J.I., 1997. The geochemistry of natural waters: surface and groundwater environments. 3rd ed., Prentice-Hall, 436 pp.

Edmunds, W.M., Bath, A.H., 1976. Centrifuge extraction and chemical analysis of interstitial waters. Environ. Sci. Technol. 10, 467-472.

Emmanuel, S., Berkowitz, B., 2007. Effects of pore-size controlled solubility on reactive transport in heterogeneous rock. Geophys. Res. Lett. 34, L06404, doi:10.1029/2006GL028962.

Gérard, F., Ranger, J., Ménétrier, C., and Bonnaud, P., 2003. Silicate weathering mechanisms determined using soil solutions held at high matric potential. Chem. Geol. 202, 443-460.

Iler, R.K., 1979. The chemistry of silica : solubility, polymerization, colloid and surface properties, and biochemistry, Wiley, New York, 866 pp.

Iwamatsu, M., Horii, K., 1996. Capillary condensation and adhesion of two wetter surfaces. J. Colloid Interf. Sci. 182, 400-406.

Kinniburgh, D.G., Miles, D.L., 1983. Extraction and chemical analysis of interstitial water from soils and rocks. Environ. Sci. Technol. 17, 362-368.

Li, Y.H., Gregory, S., 1974. Diffusion of ions in sea water and in deep sea sediments. Geochim. Cosmochim. Acta 36, 35-50.

Lyklema, J., 1991. Fundamentals of interface and colloid science. Vol. I: fundamentals (1991, 736 p.). Vol. II: solid-liquid interfaces (1995, 768 p.). Vol. III: liquid-fluid interfaces (2000, 751 p.). Academic Press. 
Mercury, L., Azaroual, M., Zeyen, H., Tardy, Y., 2003. Thermodynamic properties of solutions in metastable systems, under negative or positive pressures. Geochim. Cosmochim. Acta 67, 1769-1785.

Mizele, J., Dandurand J.L., Schott, J., 1985. Determination of the surface energy of amorphous silica from solubility measurements in micropores. Surf. Sci. 162, $830-837$.

Parkhurst, D.L., Appelo, C.A.J., 1999. User's guide to PHREEQC (Version 2) - A computer program for speciation, batch-reaction, one-dimensional transport, and inverse geochemical calculations. Water-Resources Investigations Report 99-4259, $312 \mathrm{pp}$.

Putnis, A., Mauthe, G., 2001. The effect of pore size on cementation in porous rocks. Geofluids 1, 37-41.

Reynolds, B., 1984. A simple method for the extraction of soil solution by high speed centrifugation. Plant and Soil 78, 437-440.

Richard, L.A., Weaver, L.R., 1944. Moisture retention by some irrigated soils as related to soil-moisture tension. J. Agri. Res. 69, 5, 215-235.

Rimstidt, J.D., Cole, D.R., 1983. Geothermal mineralization I: the mechanism of formation of the Beowave, Nevada, siliceous sinter deposit. Am. J. Sci. 283, $861-875$.

Saager, P.M., Sweerts, J.P., Ellermeijer, H.J., 1990. A simple pore-water sampler for coarse, sandy sediments of low porosity. Limnol. Oceanogr. 35, 747-751.

Sheppard, M.I., Thibault, D.H., Smith, P.A., 1992. Effect of Extraction Techniques on Soil Pore-Water Chemistry. Commun. Soil Sci. Plant Anal. 23(13\&14), 1643-1662.

Sjöberg, S., 1996. Silica in aqueous environments. J. Non-Cryst. Solids. 196, 51-57. 
Stumm, W., 1992. Chemistry of the solid-water interface. J. Wiley \& Sons, New York. $448 \mathrm{pp}$.

Stumm, W., Morgan, J.J., 1996. Aquatic chemistry: chemical equilibria and rates in natural waters. $3^{\text {rd }}$ ed, Wiley-Interscience, New-York, 1022 pp.

Taniguchi, H., Yoshida, T., Aoki, K., 1990. Geochemistry of volcanic product in Kozu-shima island, Izu peninsula, Japan. Kakuriken Research Paper, Tohoku Univ. $23,66-87$.

Tuller, M., Or, D., Dudley, L.M., 1999. Adsorption and capillary condensation in porous media: liquid retention and interfacial configurations in angular pores. Water Resour. Res. 35, 7, 1949-1964.

Winger, P.V., Lasier, P.J., Jackson, B.P., 1998. The influence of extraction procedure on ion concentrations in sediment pore water. Arch. Environ. Contam. Toxicol. 35, $8-13$

Yokoyama, T., Banfield, J.F., 2002. Direct determinations of the rates of rhyolite dissolution and clay formation over 52,000 years and comparison with laboratory measurements. Geochim. Cosmochim. Acta 66, 2665-2681.

Yokoyama, T., Nakashima, S., 2005. Diffusivity anisotropy in a rhyolite and its relation to pore connectivity. Eng. Geol. 80, 328-335.

Yokoyama, T., Takeuchi, S., 2009. Porosimetry of vesicular volcanic products by a water-expulsion method and the relationship of pore characteristics to permeability. J. Geophys. Res. 114, B02201, doi:10.1029/2008JB005758. 


\section{Appendix}

Disjoining pressure is described as $\Pi(h)=\Pi_{\mathrm{m}}(h)+\Pi_{\mathrm{s}}(h)+\Pi_{\mathrm{e}}(h)$ (Eq. (6)). Each of the three components can be calculated with the equations that account for the role of the nature of the substrate and the composition of the interfacial solution (e.g. Derjaguin et al., 1987). The molecular component $\Pi_{\mathrm{m}}(h)$ accounts for the solvent-substrate and substrate-substrate (opposite walls in one pore) interactions and depends both on the thickness of water film and the width of the pore. $\Pi_{\mathrm{m}}(h)$ is given by

$$
\Pi_{\mathrm{m}}(h)=A_{\mathrm{SVL}} / 6 \pi h^{3},
$$

where $h$ is the film thickness and $A_{\mathrm{svL}}$ the parameter related to the solid-vapor interaction through water film $\left(1.02 \times 10^{-20} \mathrm{~J}\right)$. The value for fused silica (Lyklema, 1991, vol. 1, p. A9.4) is used in the present study.

The structural component $\Pi_{\mathrm{s}}(h)$ relates to the changes within the solvent itself due to the proximity of the solid surfaces:

$$
\Pi_{\mathrm{s}}(h)=K \exp (-h / \lambda)
$$

where $K$ characterizes the strength of the surface field $\left(3.00 \times 10^{8} \mathrm{~N} \mathrm{~m}^{-2}\right)$ that is positive when hydrophilic structural repulsion stabilizes the film inside the two interacting objects, and $\lambda$ is the decay length of the surface forces of the order of nanometric or sub-nanometric thickness $(0.30 \mathrm{~nm})$ which depends on the hydrophilic character and the cleanness of the solid surface. These two parameters are those characteristic of quartz surfaces (Lyklema, 1991, vol. 3, p. 5.36).

The electrostatic component $\Pi_{\mathrm{e}}(h)$ is related to the diffuse double layers. In wet films, the potential $\Psi_{1}$ of a solid substrate differs from the potential $\Psi_{2}$ of the water-air interface in value and sometimes even in sign. It is generally attractive in the range 
$h<h^{\circ}$ with $h^{\circ}=1 / \kappa \times \ln \left(\Psi_{1} / \Psi_{2}\right)$, where $1 / \kappa$ (Debye radius) is a measure of the thickness of the diffuse layer. When surface potentials $\Psi_{1}$ and $\Psi_{2}$ are low, the simplified equation gives $\kappa=3.29 \times 10^{9} I^{0.5} \mathrm{~m}^{-1}$ at $25^{\circ} \mathrm{C}$, with $I$ the ionic strength (Stumm, 1992). The $\Pi_{\mathrm{e}}(h)$ can be calculated according to the following equation, provided that the surface potentials are not dependent on film thickness:

$$
\Pi_{\mathrm{e}}(h)=-\varepsilon^{\circ}\left(\Psi_{1}-\Psi_{2}\right)^{2} / 8 \pi h^{2},
$$

where $\varepsilon^{\circ}$ is the dielectric permittivity of water $\left(7.12 \times 10^{-10} \mathrm{C} \mathrm{V}^{-1} \mathrm{~m}^{-1}\right), \quad \Psi_{1}$ approximated as the surface potential (assumed as $-45 \mathrm{mV}$, slightly lower than the measured zeta potential), and $\Psi_{2}$ as the zeta potential $(-38.5 \mathrm{mV})$. 


\section{Figure captions}

Fig. 1. (a) Scanning electron microscope image of the rhyolite sample. (b) Pore size distribution of the rhyolite measured by a mercury intrusion method and cumulative pore volume ratios obtained by the mercury intrusion method and by the sequential centrifuge.

Fig. 2. Schematic illustration of centrifugal apparatus with the centrifugal force $\left(F_{\text {cent }}\right)$ and capillary force $\left(F_{\text {cap }}\right)$.

Fig. 3. Schematic diagram of the pore size distributions of water-filled pores and unfilled pores under centrifugal speeds of $960 \mathrm{rpm}$ (a) and $6070 \mathrm{rpm}(\mathrm{b})$.

Fig. 4. Result of centrifugal extraction of pore water with stepwise increase of centrifugal speed after 7 days of immersion. Solute concentrations in the pore water extracted at each centrifugal speed are plotted against the extraction ratio (= amount of extracted pore water / total amount of pore water). The results of run-A and run-B are those for the non-cleaned sample and that of run-C is for the cleaned sample. Errors are those estimated for the concentration measurements with ICP and ion chromatography. 
Fig. 5. Solute concentrations as a function of the extraction ratio obtained from the centrifugal extraction of pore water after 7 days of immersion in $\mathrm{LiBr}$ solution (run-C), one hour of immersion in $\mathrm{LiBr}$ solution (run-D) and one hour of immersion in pure water (run-E).

Fig. 6. Model illustration of the extraction process of pore water with stepwise increase of centrifugal speed. Pore water is extracted in order of large to small pores. The thickness of water film on empty pore walls changes from $3 \mathrm{~nm}$ to $1.6 \mathrm{~nm}$ with increasing centrifugal speed but this is disregarded.

Fig. 7. Concentration profiles of $\mathrm{Na}$ in pores of different radius calculated by Eq. (8) (dissolution rate $=5 \times 10^{-17} \mathrm{~mol} \mathrm{~cm} \mathrm{cec}^{-1}$ ). The dotted lines are average concentrations for each pore radius.

Fig. 8. Na concentration as a function of pore radius (extraction ratio) calculated by Eq. (9), along with the results of centrifugal extraction. Calculations were conducted for dissolution rates of $1.5 \times 10^{-16}, 3 \times 10^{-17}, 6 \times 10^{-18} \mathrm{~mol} \mathrm{~cm}^{-2} \mathrm{sec}^{-1}$.

Fig. 9. Model illustration of the time variation of the distribution of $\mathrm{Li}^{+}$in rock pores. 


\section{Table 1}

Experimental conditions for centrifugal extraction of pore waters from the rhyolite

\begin{tabular}{llll}
\hline run & Duration & Cleaned & $\mathrm{LiBr}$ addition \\
\hline A & 7 days & no & yes $\left(50 \mu \mathrm{mol} \mathrm{L}^{-1}\right)$ \\
B & 7 days & no & yes $\left(50 \mu \mathrm{mol} \mathrm{L}^{-1}\right)$ \\
C & 7 days & yes & yes $\left(50 \mu \mathrm{mol} \mathrm{L}^{-1}\right)$ \\
D & 1 hour & yes & yes $\left(50 \mu \mathrm{mol} \mathrm{L}^{-1}\right)$ \\
E & 1 hour & yes & no $($ purewater $)$ \\
\hline
\end{tabular}




\section{Table 2}

Centrifugal speed, extracted volume of pore water, pore radius, and film thickness. The values are for run-A.

\begin{tabular}{lccccccccccc}
\hline Centrifugal speed (rpm) & 0 & 530 & 960 & 1360 & 1920 & 2350 & 3040 & 4290 & 6070 & 8030 & 9600 \\
Extracted volume $(\mathrm{ml})$ & 0 & 0.402 & 0.896 & 1.317 & 1.149 & 0.728 & 0.567 & 0.433 & 0.499 & 0.243 & 0.094 \\
Extraction ratio (\%) & 0 & 5.7 & 18.5 & 37.2 & 53.6 & 63.9 & 72.0 & 78.1 & 85.2 & 88.7 & 90.0 \\
$\mathrm{r}_{\text {pore }}(\mu \mathrm{m})$ & - & 28.2 & 8.6 & 4.3 & 2.2 & 1.4 & 0.86 & 0.43 & 0.22 & 0.12 & 0.09 \\
Capillary potential (kPa) & - & 5.2 & 17 & 34 & 68 & 102 & 170 & 338 & 678 & 1186 & 1695 \\
Equivalent RH (\%) & 100 & 100 & 100 & 100 & 99.9 & 99.9 & 99.9 & 99.8 & 99.5 & 99.1 & 98.8 \\
Film thickness $(\mathrm{nm})$ & - & 3.0 & 2.8 & 2.7 & 2.5 & 2.4 & 2.2 & 2.0 & 1.8 & 1.7 & 1.6 \\
\hline
\end{tabular}




\section{Table 3}

Compositions of pore waters extracted from the rhyolite at each centrifugal speed.

\begin{tabular}{|c|c|c|c|c|c|c|c|c|c|c|c|}
\hline \multicolumn{12}{|c|}{ run-A (not cleaned, LiBr, 7d) } \\
\hline Centrifugal speed (rpm) & 0 & 530 & 960 & 1360 & 1920 & 2350 & 3040 & 4290 & 6070 & 8030 & 9600 \\
\hline Extraction ratio (\%) & 0 & 5.7 & 18.5 & 37.2 & 53.6 & 63.9 & 72.0 & 78.1 & 85.2 & 88.7 & 90.0 \\
\hline$r_{\text {pore }}(\mu \mathrm{m})$ & - & 28.2 & 8.6 & 4.3 & 2.2 & 1.4 & 0.86 & 0.43 & 0.22 & 0.12 & 0.09 \\
\hline $\mathrm{Li}^{+}\left(\mu \mathrm{mol} \mathrm{L}{ }^{-1}\right)$ & 50 & 54 & 56 & 55 & 56 & 58 & 59 & 75 & 92 & 84 & 80 \\
\hline $\mathrm{Br}^{-}\left(\mu \mathrm{mol} \mathrm{L}{ }^{-1}\right)$ & 51 & 45 & 44 & 44 & 44 & 44 & 44 & 46 & 43 & 42 & 43 \\
\hline $\mathrm{Na}^{+}\left(\mu \mathrm{mol} \mathrm{L}{ }^{-1}\right)$ & 2.0 & 39 & 35 & 33 & 35 & 34 & 53 & 81 & 146 & 160 & 242 \\
\hline $\mathrm{K}^{+}\left(\mu \mathrm{mol} \mathrm{L}^{-1}\right)$ & 0.6 & 14 & 11 & 6.2 & 8.4 & 9.2 & 14 & 28 & 63 & 59 & 104 \\
\hline $\mathrm{Ca}^{2+}\left(\mu \mathrm{mol} \mathrm{L}^{-1}\right)$ & 0.4 & 13 & 7.6 & 6.1 & 7.5 & 8.5 & 14 & 21 & 34 & 37 & 44 \\
\hline $\mathrm{Al}^{3+}\left(\mu \mathrm{mol} \mathrm{L}{ }^{-1}\right)$ & 0.5 & 3.6 & 3.1 & 1.9 & 2.4 & 2.2 & 1.9 & 3.0 & 8.1 & 14 & 12 \\
\hline $\mathrm{Fe}^{2+}+\mathrm{Fe}^{3+}\left(\mu \mathrm{mol} \mathrm{L}^{-1}\right)$ & 0.0 & 0.9 & 0.6 & 0.3 & 0.6 & 0.8 & 0.6 & 1.3 & 4.1 & 4.4 & 2.6 \\
\hline $\mathrm{Si}\left(\mu \mathrm{mol} \mathrm{L}{ }^{-1}\right)$ & 2.0 & 44 & 51 & 58 & 52 & 53 & 62 & 54 & 63 & 67 & 62 \\
\hline $\mathrm{NH}_{4}^{+}\left(\mu \mathrm{mol} \mathrm{L}{ }^{-1}\right)$ & 1.8 & 4.5 & 14 & 19 & 17 & 24 & 86 & 302 & 318 & 400 & 167 \\
\hline $\mathrm{Cl}^{-}\left(\mu \mathrm{mol} \mathrm{L}{ }^{-1}\right)$ & 1.1 & 32 & 19 & 13 & 19 & 26 & 26 & 44 & 96 & 91 & 178 \\
\hline $\mathrm{NO}_{3}^{-}\left(\mu \mathrm{mol} \mathrm{L}{ }^{-1}\right)$ & 0.7 & 13 & 4.8 & 4.3 & 6.0 & 13 & 94 & 367 & 438 & 558 & 290 \\
\hline
\end{tabular}


Table 3 (continued)

\begin{tabular}{lcccccccccc}
\hline run-B (not cleaned, $\mathrm{LiBr}, 7 \mathrm{~d})$ & & & & & & & & & \\
\hline Centrifugal speed $(\mathrm{rpm})$ & 0 & 530 & 960 & 1360 & 1920 & 2350 & 3040 & 4290 & 6070 & 8030 \\
Extraction ratio (\%) & 0 & 6.8 & 19.4 & 34.4 & 48.7 & 59.9 & 70.5 & 77.6 & 84.3 & 88.9 \\
$\mathrm{r}_{\text {pore }}(\mu \mathrm{m})$ & - & 28.2 & 8.6 & 4.3 & 2.2 & 1.4 & 0.86 & 0.43 & 0.22 & 0.12 \\
$\mathrm{Li}^{+}\left(\mu \mathrm{mol} \mathrm{L}^{-1}\right)$ & 50 & 51 & 56 & 56 & 57 & 57 & 61 & 64 & 65 & 64 \\
$\mathrm{Br}^{-}\left(\mu \mathrm{mol} \mathrm{L}^{-1}\right)$ & 51 & 49 & 45 & 45 & 47 & 48 & 48 & 48 & 49 & 48 \\
$\mathrm{Na}^{+}\left(\mu \mathrm{mol} \mathrm{L}^{-1}\right)$ & 2.0 & 34 & 29 & 26 & 29 & 34 & 54 & 58 & 87 & 85 \\
$\mathrm{~K}^{+}\left(\mu \mathrm{mol} \mathrm{L}^{-1}\right)$ & 0.6 & 15 & 8.1 & 5.5 & 6.1 & 9.5 & 18 & 22 & 44 & 30 \\
$\mathrm{Ca}^{2+}\left(\mu \mathrm{mol} \mathrm{L}^{-1}\right)$ & 0.4 & 20 & 6.4 & 9.7 & 7.3 & 9.9 & 14 & 18 & 26 & 29 \\
$\mathrm{Al}^{3+}\left(\mu \mathrm{mol} \mathrm{L}^{-1}\right)$ & 0.5 & 3.9 & 4.9 & 4.0 & 4.6 & 4.5 & 3.9 & 3.8 & 8.6 & 5.6 \\
$\mathrm{Fe}^{2+}+\mathrm{Fe}^{3+}(\mu \mathrm{mol} \mathrm{L}$ \\
$\mathrm{Si}^{-1}(\mu \mathrm{mol} \mathrm{L}$
\end{tabular}


Table 3 (continued)

\begin{tabular}{|c|c|c|c|c|c|c|c|c|c|c|c|}
\hline \multicolumn{12}{|l|}{ run-C (cleaned, LiBr, 7d) } \\
\hline Centrifugal speed (rpm) & 0 & 530 & 960 & 1360 & 1920 & 2350 & 3040 & 4290 & 5260 & 6790 & 8590 \\
\hline Extraction ratio (\%) & 0.0 & 7.6 & 20.4 & 38.5 & 55.8 & 64.2 & 73.7 & 81.1 & 84.5 & 88.0 & 90.5 \\
\hline$r_{\text {pore }}(\mu \mathrm{m})$ & - & 28.2 & 8.6 & 4.3 & 2.2 & 1.4 & 0.86 & 0.43 & 0.29 & 0.17 & 0.11 \\
\hline $\mathrm{pH}$ & 6.2 & 5.6 & 5.4 & 5.5 & 5.5 & 5.5 & 5.5 & 5.6 & 5.5 & 5.2 & 5.6 \\
\hline $\mathrm{Li}^{+}\left(\mu \mathrm{mol} \mathrm{L}{ }^{-1}\right)$ & 48 & 59 & 51 & 46 & 46 & 43 & 46 & 53 & 81 & 107 & 66 \\
\hline $\mathrm{Br}^{-}\left(\mu \mathrm{mol} \mathrm{L}{ }^{-1}\right)$ & 50 & 50 & 47 & 46 & 46 & 43 & 45 & 46 & 50 & 46 & 53 \\
\hline $\mathrm{Na}^{+}\left(\mu \mathrm{mol} \mathrm{L}{ }^{-1}\right)$ & 4.5 & 41 & 23 & 24 & 23 & 23 & 25 & 33 & 90 & 152 & 130 \\
\hline $\mathrm{K}^{+}\left(\mu \mathrm{mol} \mathrm{L}^{-1}\right)$ & 0.4 & 13 & 4.2 & 4.5 & 3.4 & 4.6 & 4.4 & 5.6 & 53 & 114 & 44 \\
\hline $\mathrm{Ca}^{2+}\left(\mu \mathrm{mol} \mathrm{L}^{-1}\right)$ & 0.0 & 13 & 4.7 & 6.1 & 4.2 & 5.6 & 4.1 & 5.9 & 16 & 33 & 13 \\
\hline $\mathrm{Si}\left(\mu \mathrm{mol} \mathrm{L}{ }^{-1}\right)$ & 6.6 & 46 & 66 & 88 & 89 & 104 & 100 & 87 & 81 & 81 & 135 \\
\hline $\mathrm{NH}_{4}^{+}\left(\mu \mathrm{mol} \mathrm{L}{ }^{-1}\right)$ & 0.3 & 15 & 3.2 & 1.4 & 4.3 & 5.2 & 2.7 & 5.5 & 31 & 54 & 38 \\
\hline $\mathrm{Cl}^{-}\left(\mu \mathrm{mol} \mathrm{L}^{-1}\right)$ & 0.0 & 31 & 11 & 9.9 & 8.9 & 12 & 12 & 19 & 71 & 111 & 102 \\
\hline $\mathrm{NO}_{3}^{-}\left(\mu \mathrm{mol} \mathrm{L}{ }^{-1}\right)$ & 0.0 & 13 & 3.7 & 3.0 & 2.2 & 3.3 & 3.2 & 5.9 & 11 & 13 & 15 \\
\hline
\end{tabular}


Table 3 (continued)

\begin{tabular}{|c|c|c|c|c|c|c|}
\hline run-D (cleaned, LiBr, 1h) & & & & & & \\
\hline Centrifugal speed (rpm) & 0 & 960 & 1360 & 2150 & 4290 & 6790 \\
\hline Extraction ratio (\%) & 0.0 & 20.3 & 36.3 & 60.6 & 82.5 & 90.0 \\
\hline$r_{\text {pore }}(\mu \mathrm{m})$ & - & 8.6 & 4.3 & 1.7 & 0.43 & 0.17 \\
\hline $\mathrm{Li}^{+}(\mu \mathrm{mol} \mathrm{L}-1)$ & 48 & 33 & 26 & 23 & 25 & 29 \\
\hline $\operatorname{Br}^{-}\left(\mu \mathrm{mol} \mathrm{L}^{-1}\right)$ & 50 & 52 & 51 & 51 & 50 & 49 \\
\hline $\mathrm{Na}^{+}\left(\mu \mathrm{mol} \mathrm{L}{ }^{-1}\right)$ & 2.6 & 29 & 41 & 49 & 55 & 60 \\
\hline $\mathrm{K}^{+}\left(\mu \mathrm{mol} \mathrm{L}{ }^{-1}\right)$ & 0.0 & 3.4 & 3.0 & 3.4 & 3.7 & 4.3 \\
\hline $\mathrm{Ca}^{2+}\left(\mu \mathrm{mol} \mathrm{L}^{-1}\right)$ & 0.0 & 6.6 & 3.9 & 6.5 & 7.9 & 11 \\
\hline Si $\left(\mu \mathrm{mol} \mathrm{L}^{-1}\right)$ & 0.0 & 7.0 & 17 & 22 & 30 & 41 \\
\hline $\mathrm{NH}_{4}^{+}\left(\mu \mathrm{mol} \mathrm{L}^{-1}\right)$ & 2.3 & 11 & 13 & 13 & 11 & 16 \\
\hline $\mathrm{Cl}^{-}\left(\mu \mathrm{mol} \mathrm{L}{ }^{-1}\right)$ & 1.0 & 4.6 & 4.3 & 5.7 & 5.4 & 13 \\
\hline
\end{tabular}


Table 3 (continued)

\begin{tabular}{|c|c|c|c|c|c|c|}
\hline \multicolumn{7}{|c|}{ run-E (cleaned, purewater, $1 \mathrm{~h}$ ) } \\
\hline Centrifugal speed (rpm) & 0 & 960 & 1360 & 2150 & 4290 & 6790 \\
\hline Extraction ratio (\%) & 0.0 & 21.1 & 37.5 & 60.3 & 84.5 & 90.5 \\
\hline$r_{\text {pore }}(\mu \mathrm{m})$ & - & 8.6 & 4.3 & 1.7 & 0.43 & 0.17 \\
\hline $\mathrm{Li}^{+}(\mu \mathrm{mol} \mathrm{L}-1)$ & 0.0 & 1.2 & 1.6 & 3.7 & 2.2 & 5.9 \\
\hline $\operatorname{Br}^{-}\left(\mu \mathrm{mol} \mathrm{L}^{-1}\right)$ & 0.0 & 0.0 & 0.0 & 0.0 & 0.0 & 0.0 \\
\hline $\mathrm{Na}^{+}\left(\mu \mathrm{mol} \mathrm{L}{ }^{-1}\right)$ & 1.4 & 18 & 26 & 30 & 41 & 56 \\
\hline $\mathrm{K}^{+}\left(\mu \mathrm{mol} \mathrm{L}{ }^{-1}\right)$ & 0.5 & 2.4 & 3.0 & 2.8 & 3.5 & 6.6 \\
\hline $\mathrm{Ca}^{2+}\left(\mu \mathrm{mol} \mathrm{L}^{-1}\right)$ & 0.0 & 5.0 & 6.9 & 6.6 & 5.7 & 15 \\
\hline Si $\left(\mu \mathrm{mol} \mathrm{L}^{-1}\right)$ & 0.0 & 7.7 & 14 & 17 & 29 & 35 \\
\hline $\mathrm{NH}_{4}^{+}\left(\mu \mathrm{mol} \mathrm{L}^{-1}\right)$ & 1.5 & 11 & 12 & 12 & 13 & 18 \\
\hline $\mathrm{Cl}^{-}\left(\mu \mathrm{mol} \mathrm{L}{ }^{-1}\right)$ & 0.9 & 7.7 & 7.7 & 9.0 & 9.7 & 25 \\
\hline
\end{tabular}


Fig. 1
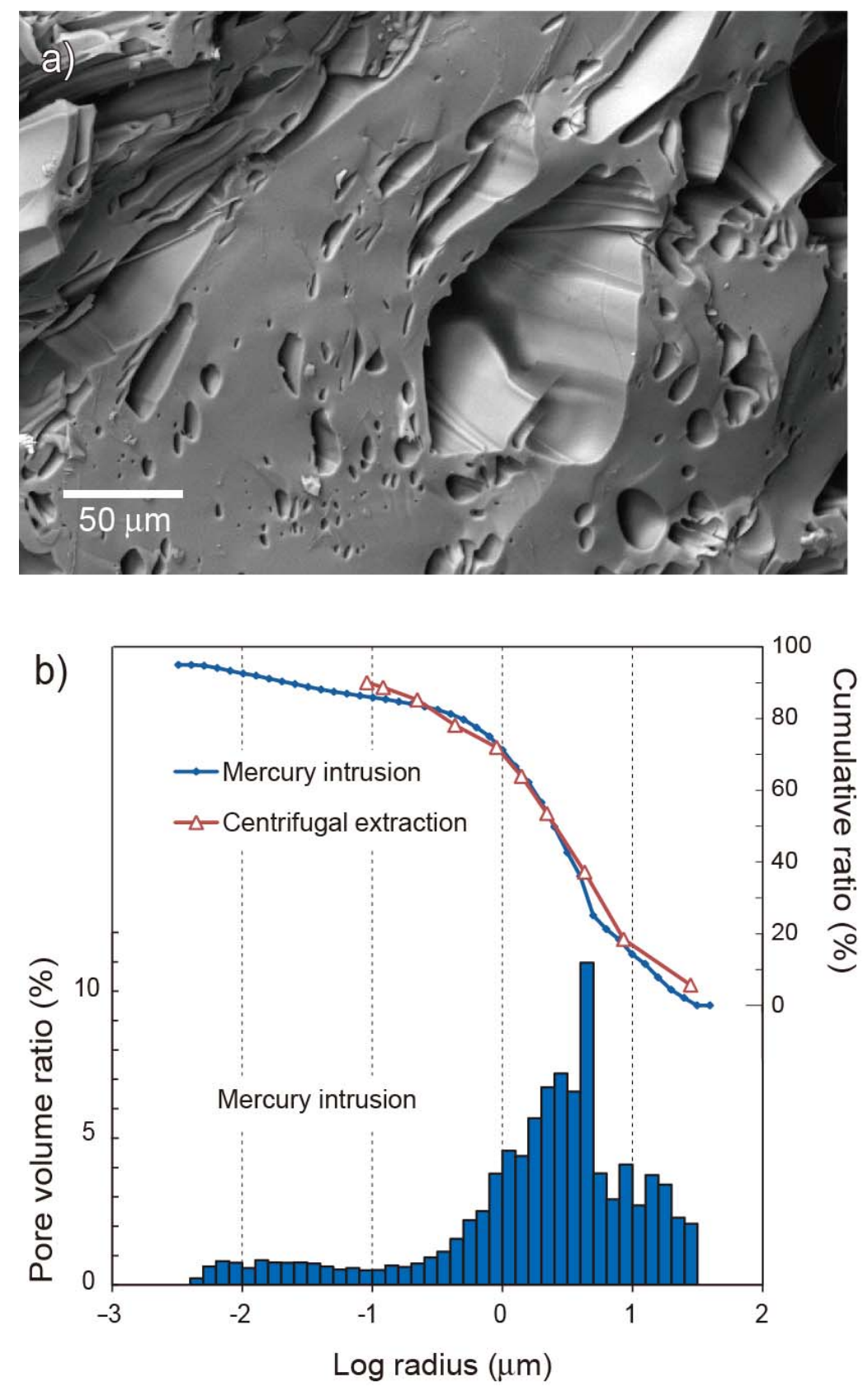
Fig. 2

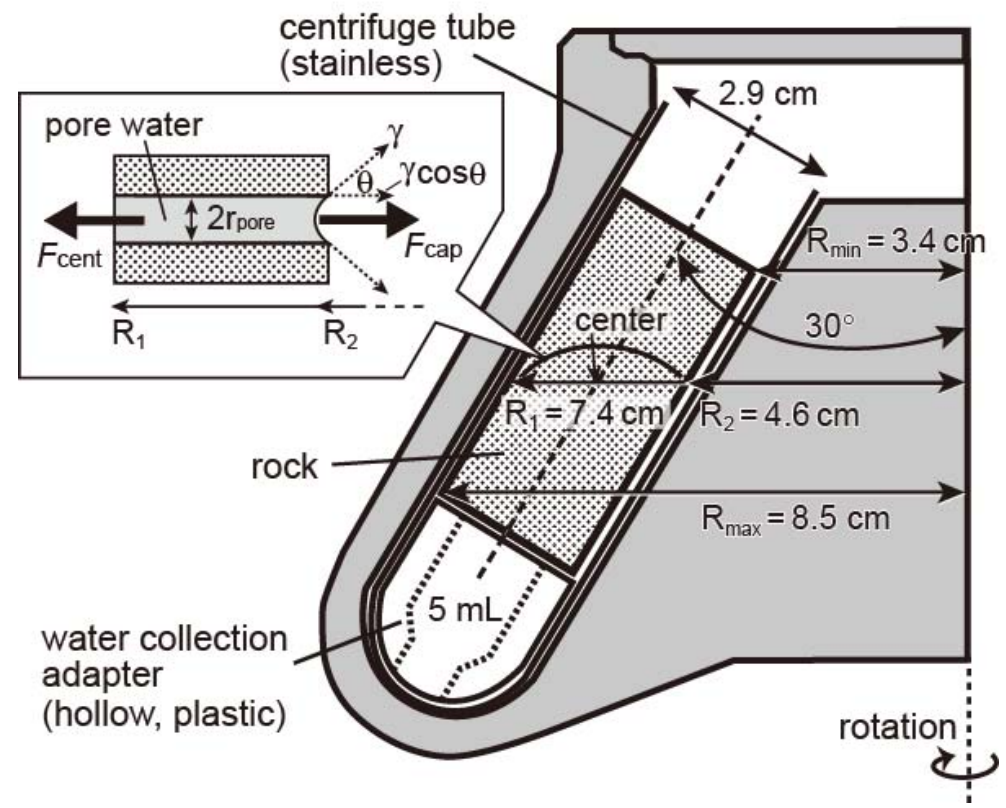


Fig. 3
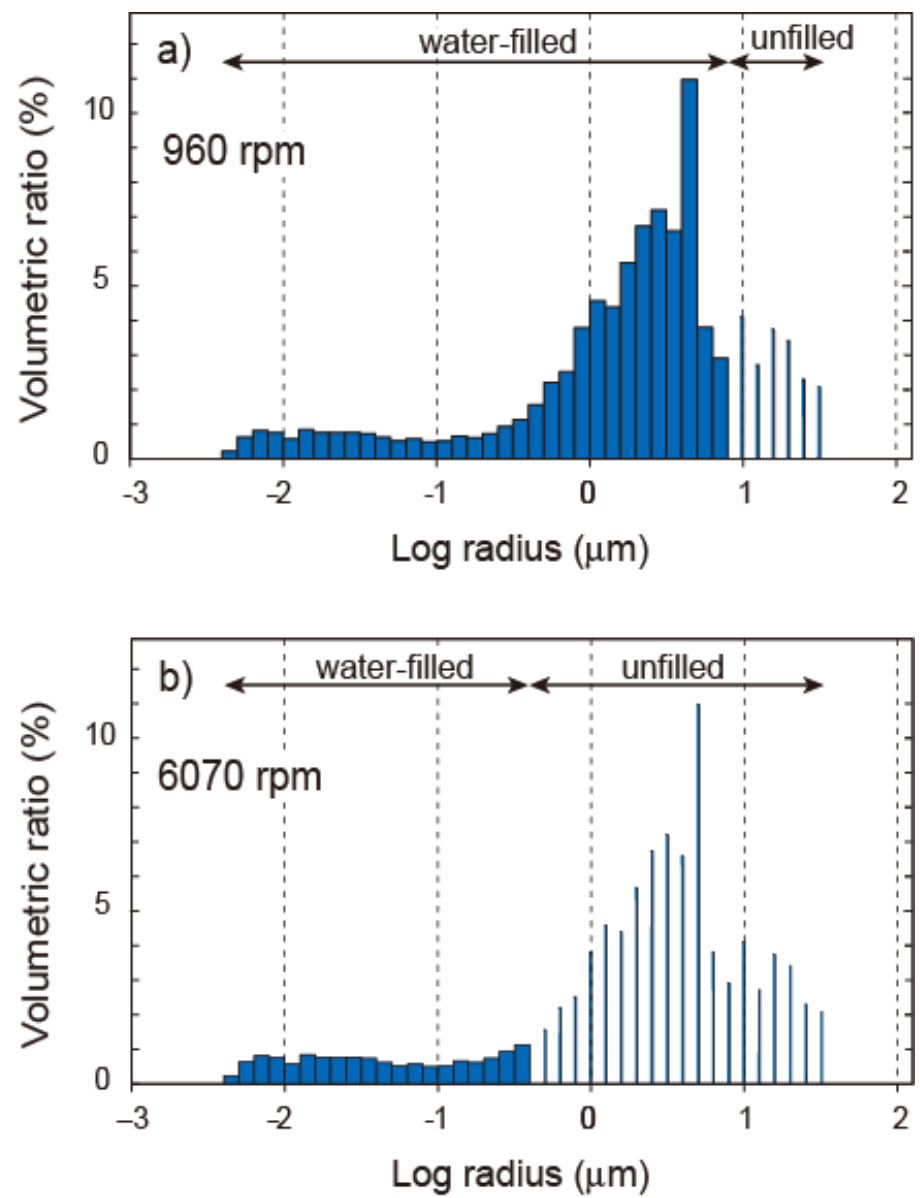
Fig. 4
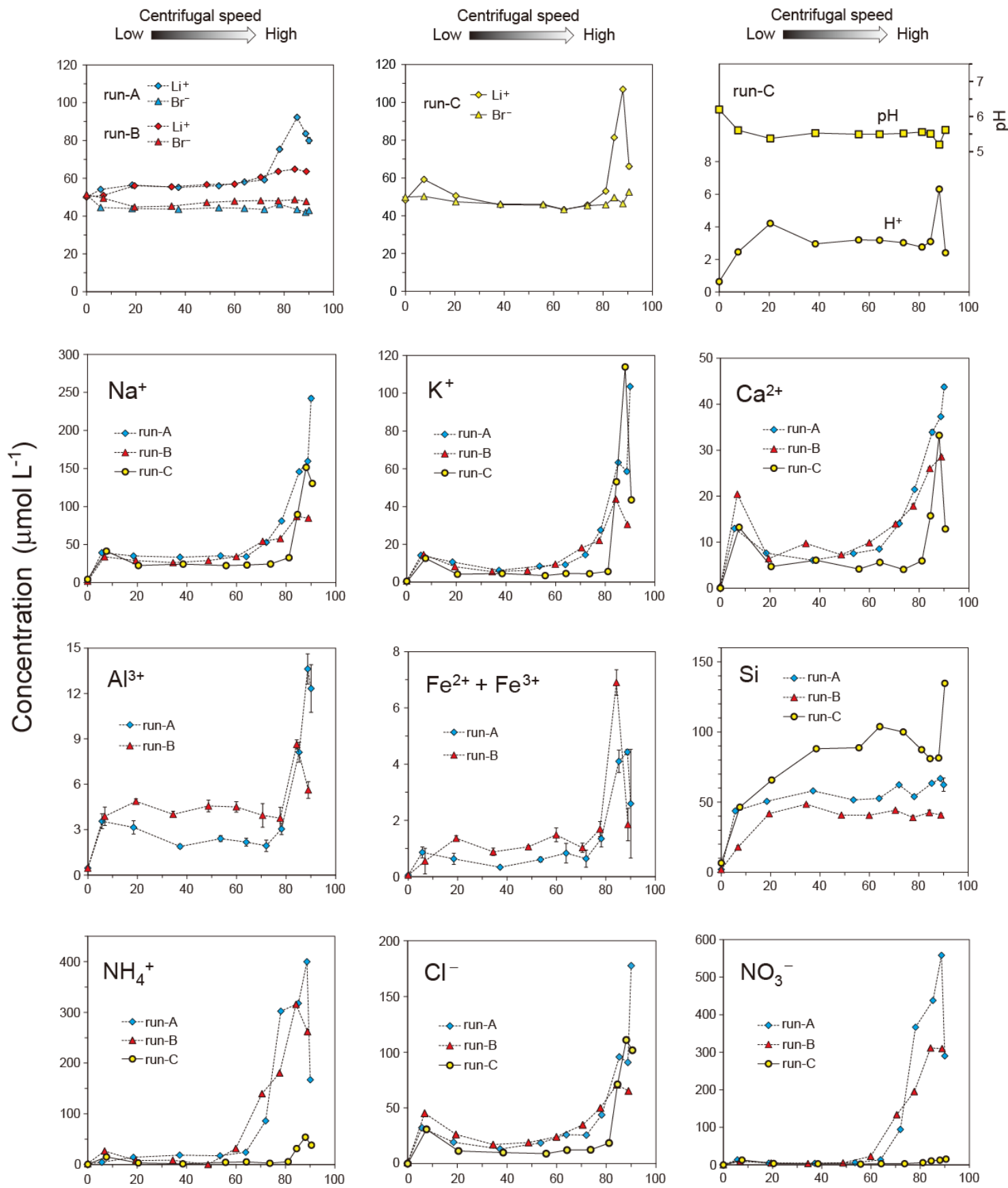

Extraction ratio (\%)
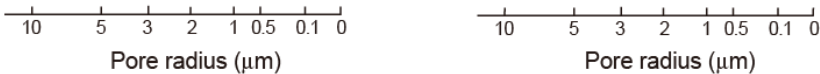
Pore radius $(\mu \mathrm{m})$

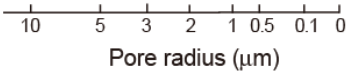


Fig. 5
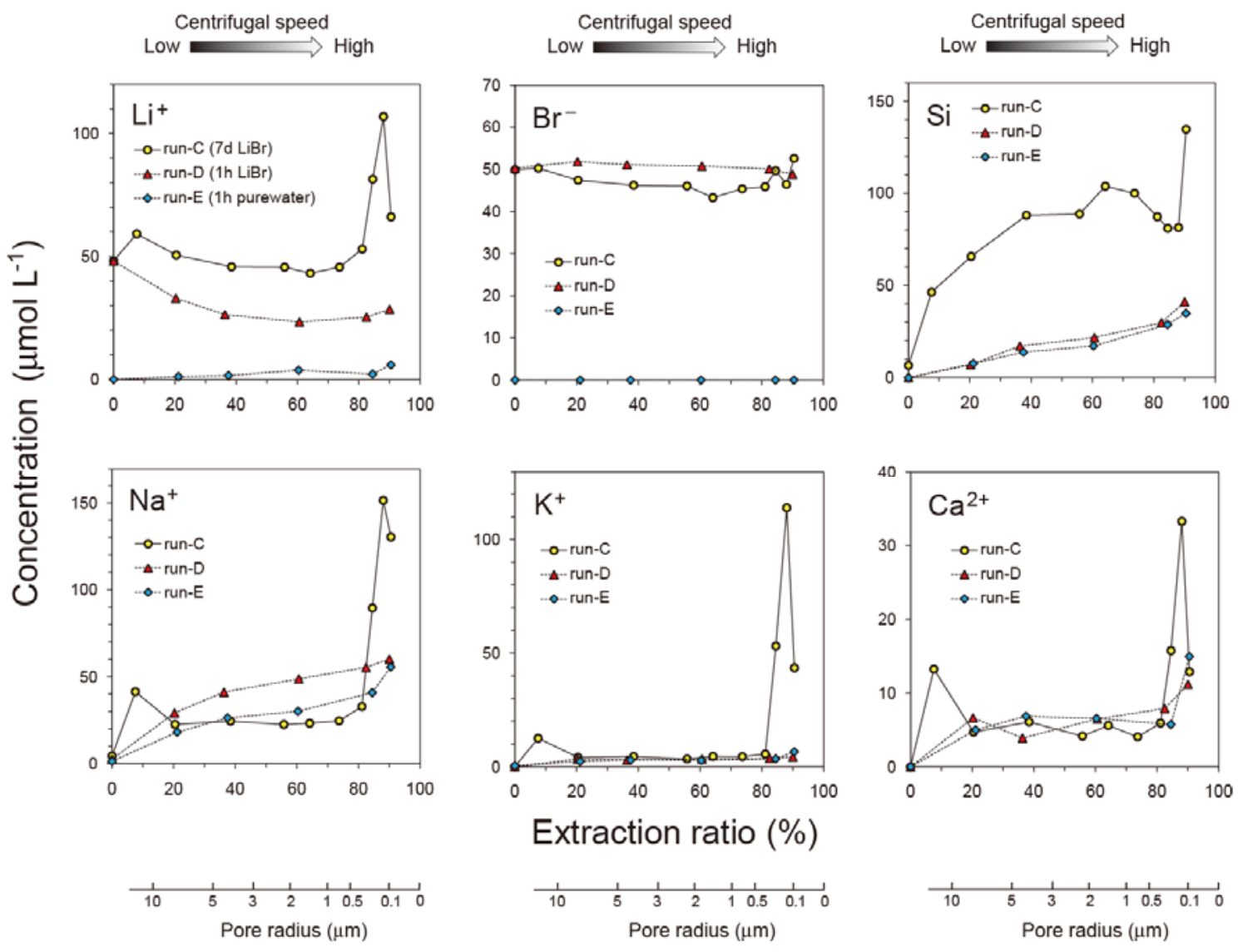

Extraction ratio (\%)
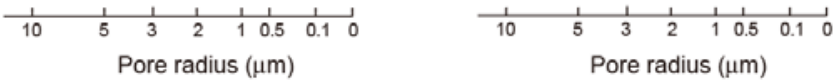
Fig. 6

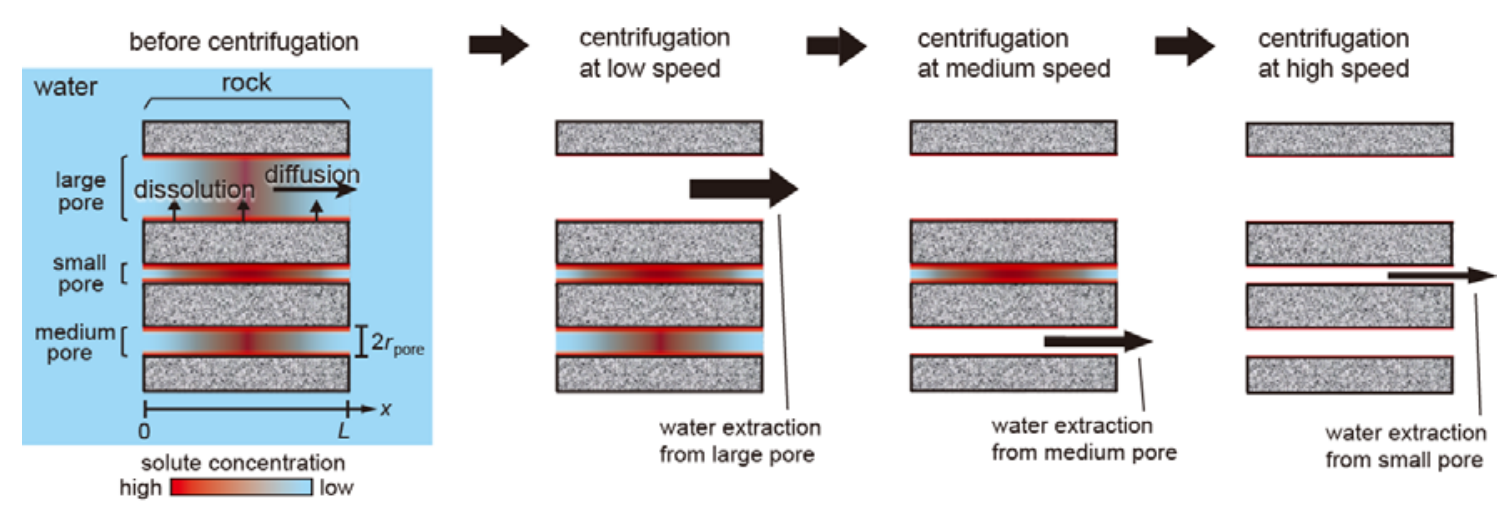


Fig. 7

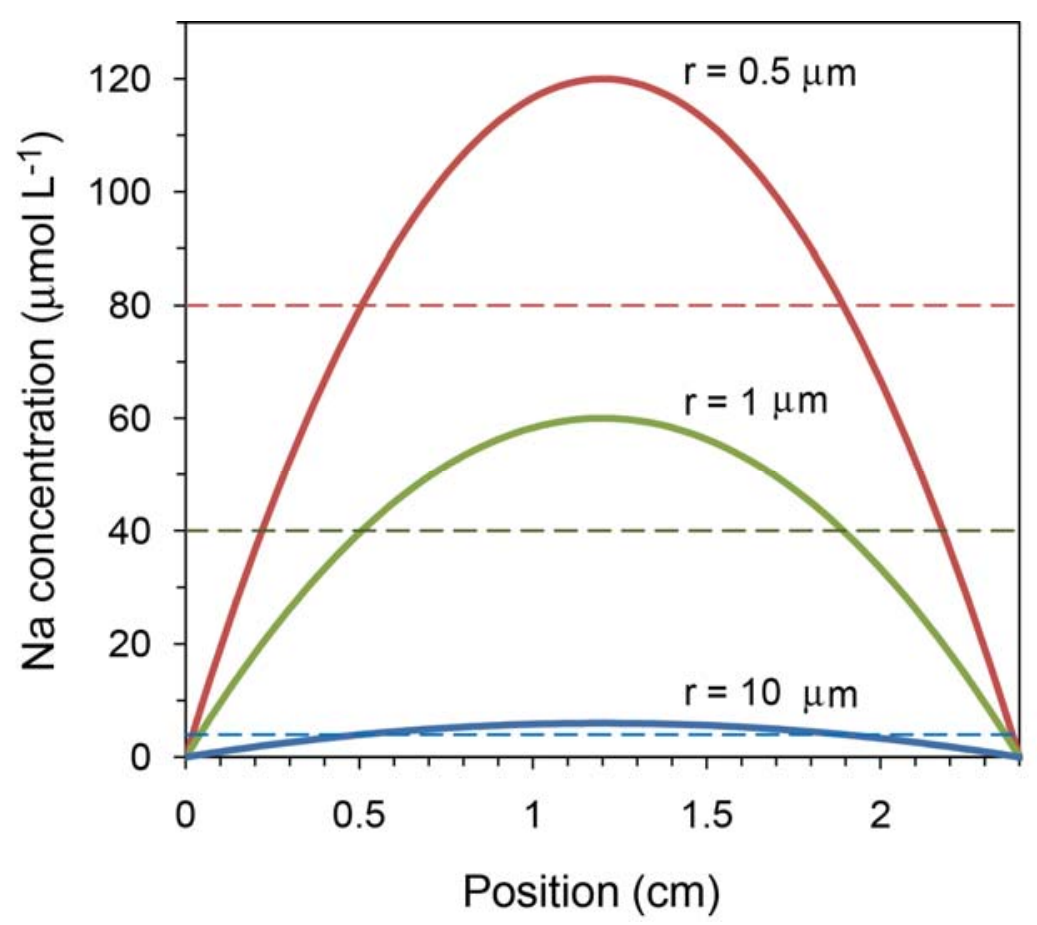


Fig. 8

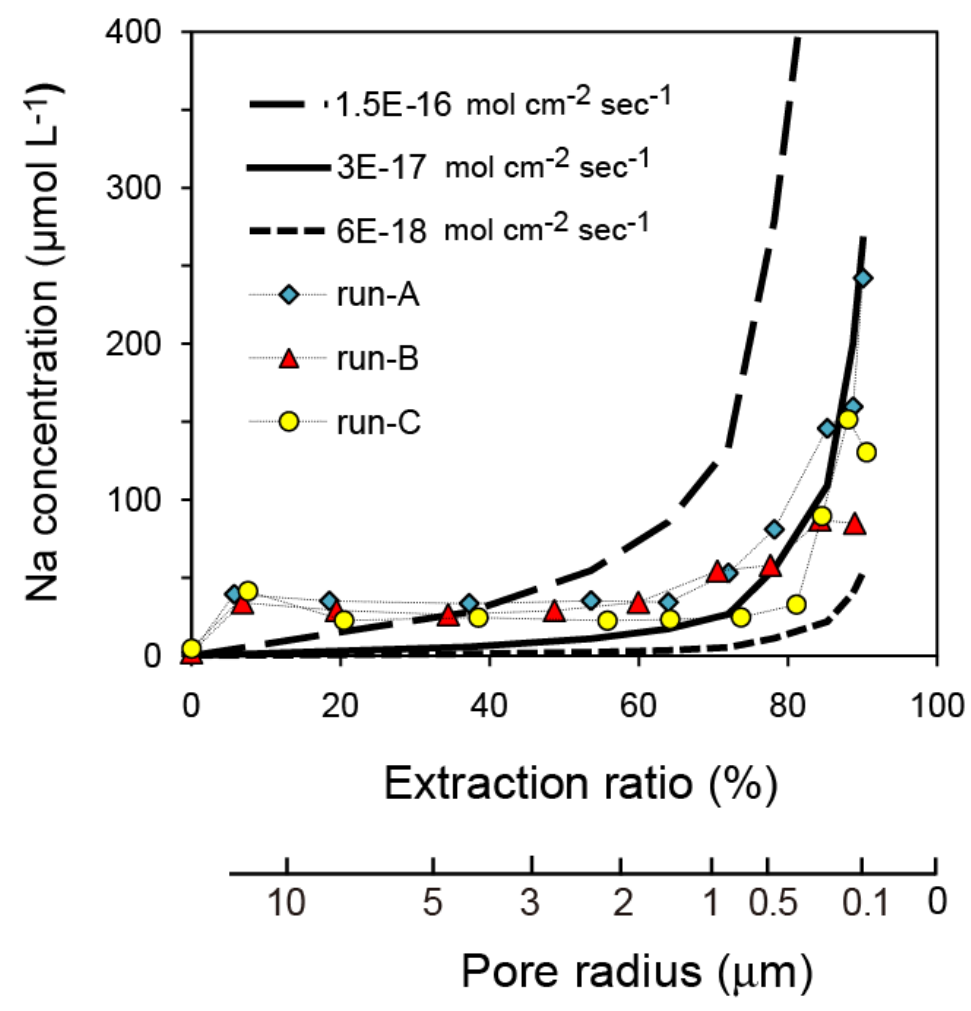


Fig. 9

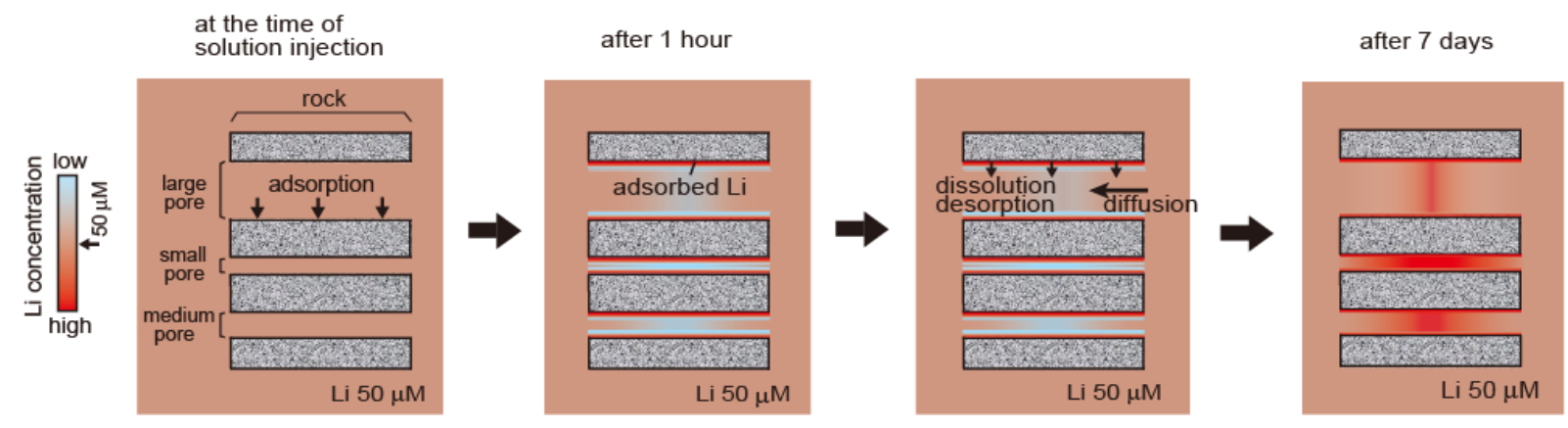

